\title{
Polysulfone/Cellulose Acetate Butyrate Environmentally Friendly Blend to minimize the Impact of UV Radiation
}

\author{
Raouf RM ${ }^{1,2 *}$, Wahab ZA ${ }^{1}$, Ibrahim $N^{3,4}$ and Talib ZA ${ }^{1}$ \\ ${ }^{1}$ Department Of Physics, Universiti Putra Malaysia, 43400 UPM Serdang, Selangor, Malaysia \\ ${ }^{2}$ Materials Engineering Department, College of Engineering, Al-Mustansiriyah University, Baghdad, Iraq \\ ${ }^{3}$ Department Of Chemistry, Faculty of Science, Universiti Putra Malaysia, 43400 UPM Serdang, Selangor, Malaysia \\ ${ }^{4}$ Materials Processing and Technology Laboratory, Institute of Advanced Technology, Universiti Putra Malaysia, 43400 UPM Serdang, Selangor, Malaysia
}

\begin{abstract}
An eco-friendly transparent blend for ultraviolet and visible light rays from polysulfone (PSF) and cellulose acetate butyrate $(C A B)$ was prepared by melting and re-molding. Some optical, mechanical, thermal and morphological properties of the blend were studied by means of UV-Vis spectroscopy, dynamic mechanical analysis (DMA), thermogravimetric analysis (TGA), scanning electron microscope (SEM) and X-ray diffraction (XRD). The UV-Vis spectroscopy results showed that the blend became more transparent in the ultraviolet region with an increase in $\mathrm{CAB}$ concentration, especially at the damage threshold $(268 \mathrm{~nm})$. The preferable blend sample contained $0.2 \% \mathrm{w} / \mathrm{w}$ CAB in the PSF/CAB blend, signifying low ultraviolet light absorption while preserving the transparency of the blend. The results also demonstrated that the amount of $0.2 \%$ CAB in PSF increased the modulus and thermal stability while decreasing the value of the glass transition temperature.
\end{abstract}

Keywords: Blend; Cellulose acetate butyrate (CAB); Polysulfone (PSF); Ultraviolet

\section{Introduction}

Polymer blend is a combination of two polymers or composites at least. The purpose of polymer blending is to obtain a new material with different physical properties to meet performance requirements that cannot be satisfied by the currently available polymer. There are two ways to blend polymers. One is by blending the compound component in the molten state; the other is to blend them in common solution [1]. Melting by using the twin screw extruder (used in this work) is the other method. The twin screw extruder is preferred for melt-blending polymers with added materials instead of using a single screw extruder because of several issues, including its extraordinary mixing ability, the high degree of process resilience, better control of process parameters, and higher process productivity. Therefore, mixing and melting two materials for the purpose of forming a homogeneous blend or composite will be easier and more accurate by using the twin screw extruder $[2,3]$.

In recent years, much attention has been focused on environmentally friendly materials as a renewable source to reduce the amount of waste that accumulates on the Earth. Therefore, inserting renewable polymeric materials in the blend has become the focus of many academic studies and industrial undertakings [4-7]. Renewable polymeric materials carry a higher grade of complexity than artificial ones. This is the result of nature's long growth in terms of material design, which is of great importance to many applications. Natural polymers have numerous positive properties compared to artificial polymers that make them ideal applicants for different applications.

Conversely, there are numerous disadvantages of biodegradable polymers obtained from renewable sources, such as unacceptable mechanical properties especially under wet conditions, solubility in water, and the rapid degradation rate. Although there is no ideal polymeric blend or composite from renewable resources, the properties of polymer blends can notably improve by blending synthetic polymers with natural polymers $[8,9]$.

Bio-based cellulose acetate butyrate $(\mathrm{CAB})$ is a thermoplastic polymer, obtained from the esterification of acetyl and butyryl group.
This polymer has showed its significance in different applications in terms of transparency and weathering resistance when used as a coating to repair or re-finish, and especially for ultraviolet protection, in addition to the high usability of casting and molding. Therefore, $\mathrm{CAB}$ is used as biodegradable inhibitor with polymers. The biodegradation inhibitor has postulated that the change in the biodegradability of the blend with $\mathrm{CAB}$ was caused by the new structural phase formed when $\mathrm{CAB}$ is added to the blend [10-13].

Polysulfone (PSF) is also a thermoplastic polymer like cellulose acetate butyrate (CAB). It is well known for its transparency, toughness, high strength and high thermal stability. In some applications, it is used as a substitute for polycarbonate because of its unique properties, but its low resistance to a number of solvents and rapid weathering restricts its applications $[14,15]$.

Studies have confirmed that the microstructure and the performance of PSF are affected by ultraviolet irradiation within a very short time of exposure, leading to simultaneous chain scission and crosslinking [16]. PSF photooxidation in an oxygen atmosphere leads to an oxidized surface with an increase in the relative amount of sulphur on the surface. This change is attributed to rapid oxidation at carbon sites in the polymer [17]. At temperatures below $140^{\circ} \mathrm{C}$, long heating times cause little changes in the PSF properties, but exposure to ultraviolet light results in greater changes, as indicated by broad absorption in both the carbonyl and hydroxyl areas [18].

The purpose of this work is to make the PSF/CAB blend more

*Corresponding author: Raouf RM, Faculty of Science, Department Of Physics Universiti Putra Malaysia, 43400 UPM Serdang, Selangor, Malaysia, Tel: 60389466000 ; E-mail: raoufmahmood@yahoo.com

Received November 19, 2015; Accepted December 04, 2015; Published December 14,2015

Citation: Raouf RM, Wahab ZA, Ibrahim NA, Talib ZA (2015) Polysulfone/Cellulose Acetate Butyrate Environmentally Friendly Blend to minimize the Impact of UV Radiation. J Material Sci Eng 5: 219. doi:10.4172/2169-0022.1000219

Copyright: ( 2015 Raouf RM, et al. This is an open-access article distributed under the terms of the Creative Commons Attribution License, which permits unrestricted use, distribution, and reproduction in any medium, provided the original author and source are credited. 
transparent in the UV region in order to reduce the damage that is caused from trapped radiation inside the material, and to withstand weather conditions.

\section{Experimental}

\section{Materials}

Transparent pellets of polysulfone (PSF; average $\mathrm{M}_{\mathrm{w}} \sim 35,000$ by LS, average $M_{n} \sim 16,000$ by $M O$ ) and white powder cellulose acetate butyrate (CAB; average $M_{n} \sim 12,000$ ) were supplied by Sigma-Aldrich(USA).

\section{Methods}

The samples were prepared using twin screw (three zones, electric heating and air cooling) Thermo-Haake Poly Drive Internal Mixer (Germany) $(\mathrm{D}=19.05 \mathrm{~mm})$ and Hsin-Chi Machinery Co. Ltd. hot press (Taiwan). The materials were dried in a vacuum oven at $50^{\circ} \mathrm{C}$ for $4 \mathrm{~h}$ before mixing. The CAB/PSF blends were prepared by adding a fixed weight of PSF to different weight ratio of CAB. Firstly, the polymer pellets was melt-kneaded in the extruder at a rotation rate of 50 $\mathrm{rpm}$ at $225^{\circ} \mathrm{C}$ for $10 \mathrm{~min}$. Then, variable percentage weights of $\mathrm{CAB}$ $(0.1 \%, 0.2 \%, 0.3 \%$ and $0.4 \%)$ were added to the molten of PSF. Mixing continued until reached to constant torque, which took about 10-15 min. The samples were transparent and homogeneous in their outward appearance. After that, each blended sample was pressed in a hot press at $110 \mathrm{KPa}$ and $130^{\circ} \mathrm{C}$ to form a sheet $70 \mathrm{~mm} \times 90 \mathrm{~mm}, 1 \mathrm{~mm}$ thick.

\section{Measurements}

The character of the transparency and absorbance of the samples was determined using ultraviolet-visible (UV-VIS) spectroscopy (Shimadzu UV-3600 spectrophotometer, Japan). Surface analysis was obtained out by scanning electron microscopy (SEM) studies on a Hitachi S-3400N (Japan) microscope. Sample morphology and crystallinity identification were determined by XRD analysis using a X-ray diffractometer (Philips/X'Pert Pro Panalytical - PW 3040/60 MPD, Netherlands). The diffractometer data were obtained from $2 \Theta=20^{\circ} \mathrm{C}$ to $80^{\circ}$ at a scanning speed of $5^{\circ} \mathrm{C} / \mathrm{min}$. Dynamic mechanical analysis (DMA) was made on a PerkinElmer Pyris Diamond (USA) apparatus in tension mode at a frequency of $1 \mathrm{~Hz}$ and a heating rate of $5^{\circ} \mathrm{C} / \mathrm{min}$ in a liquid nitrogen atmosphere. Thermal gravimetric analysis (TGA) was undertaken on a TGA/DSC1 STAR System (USA) at a heating rate of $20^{\circ} \mathrm{C} / \mathrm{min}$ from room temperature to $1000^{\circ} \mathrm{C}$ in a continuous highly pure nitrogen atmosphere.

\section{Characterization}

Complete scans over the ultraviolet and visible spectra were made from $220 \mathrm{~nm}$ to $800 \mathrm{~nm}$ for highly transparent pure PSF samples using a Shimadzu UV-3600 spectrophotometer. The results show that the absorbance peak in the ultraviolet range for pure PSF was at $268 \mathrm{~nm}$, which represents the UV damage peak for the polymers [19-21], whilst the transmittance peak in the visible range for pure PSF was $712.5 \mathrm{~nm}$. The transmittance peak indicates the real effectiveness for pure PSF [21]. The absorbance and transmittance peak values were adopted for all subsequent measurements on the blended samples under study, as well as the sample transparency.

\section{Results and Discussion}

\section{UV-VIS spectroscopy}

The absorbance and transmittance curves, in addition to the spectra and the visual appearance of the PSF and PSF-CAB blends are shown in Figure 1.
The $\mathrm{CAB}$ concentration in PSF was $0.1,0.2,0.3$ and $0.4 \%$. Figure 1a shows the relationship between absorbance and concentration for PSF at $268 \mathrm{~nm}$. It is clear that an increase in the CAB concentration in PSF reduced the optical absorbance in the ultraviolet area, especially at the damage threshold $(268 \mathrm{~nm})$. The retention of ultraviolet radiation within PSF molecules leads to the breakdown of bonds in the polymeric chain and disintegration over time. Therefore, a change in physical properties will take place, which reduces the lifetime of utilization [18]. On the other hand, the optical transmittance in the visible region, especially at a wavelength of $712.5 \mathrm{~nm}$, was relatively stable at the first two concentrations, then declined from $0.2 \%$ to $0.4 \%$; this is evident from the foggy samples shown in Figure 1d. Therefore, $0.2 \%$ CAB was the best concentration of PSF in terms of the lack of absorption in the mid-ultraviolet region and the maintenance of optical transmittance with the required transparency.

In the PSF-CAB blends, it was noted that the samples were transparent down to $0.3 \%$; after that, the samples started to become hazy with an increasing $\mathrm{CAB}$ concentration in PSF. Samples with concentrations more than $0.4 \%$ were discarded because they did not meet the required purpose.

\section{Scanning electron microscopy}

The SEM images taken for the internal morphological study of pure PSF and PSF/0.2\% CAB blend are shown in Figure 2. The SEM images for each sample are shown at three different magnifications (2, $5,10 \mu \mathrm{m})$. As can be seen in the pure PSF images, there were uniform morphological features, indicating a single material (Figures 2a-2c) [22].

The morphology of PSF/0.2\% CAB blend shown in Figure $2 \mathrm{~d}-2 \mathrm{f}$. It is easy to see the size reduction of the $\mathrm{CAB}$ components and separation from the continuous phase of PSF. Figure $2 \mathrm{f}$ shows that the size of $\mathrm{CAB}$ sphere not more than $(99.5 \mathrm{~nm})$. In polymer blends, if the concentration of one components is small, it tend to present in spherical droplets dispersed all over the matrix and the polymer nature determined the size [23]. The clear difference in the size of the spherical shapes may be due to variation in the interaction between functional components that led to an increase or decrease the surface tension [24,25]. As a result foggy appeared as early as in low concentrations of CAB in PSF.

\section{$\mathrm{X}$-Ray diffraction}

The X-ray diffraction pattern of pure PSF and PSF/0.2\% CAB blend are shown in Figure 3. The patterns in Figures $3 \mathrm{a}$ and $3 \mathrm{~b}$ show that there were no clear peaks. The broadened background scattering areas of pure PSF indicate their amorphous nature and non-crystalline structure [26-28]. So, change absence that observed in the pure polymer to the blends indicates that $\mathrm{CAB}$ did not change the essential random compositional structure of the original polymer. This corresponds with previous data indicating that the spherical clusters were no larger than $99.5 \mathrm{~nm}$ in PSF/0.2\% CAB, i.e., are not crystalline regions.

\section{Dynamic mechanical analysis}

The dynamic mechanical analysis is a technique involves studying the properties of materials as they are deformed under periodic stress by applying a variable sinusoidal stress under thermal conditions. Most polymers are viscoelastic and exhibit a phase difference between applied stress and the resultant sinusoidal strain. This phase difference, together with the amplitudes of the stress and strain waves, is used to determine a variety of parameters, including storage modulus E' (the ability of the material to store potential energy), loss modulus E" (energy 
Citation: Raouf RM, Wahab ZA, Ibrahim NA, Talib ZA (2015) Polysulfone/Cellulose Acetate Butyrate Environmentally Friendly Blend to minimize the Impact of UV Radiation. J Material Sci Eng 5: 219. doi:10.4172/2169-0022.1000219

Page 3 of 7

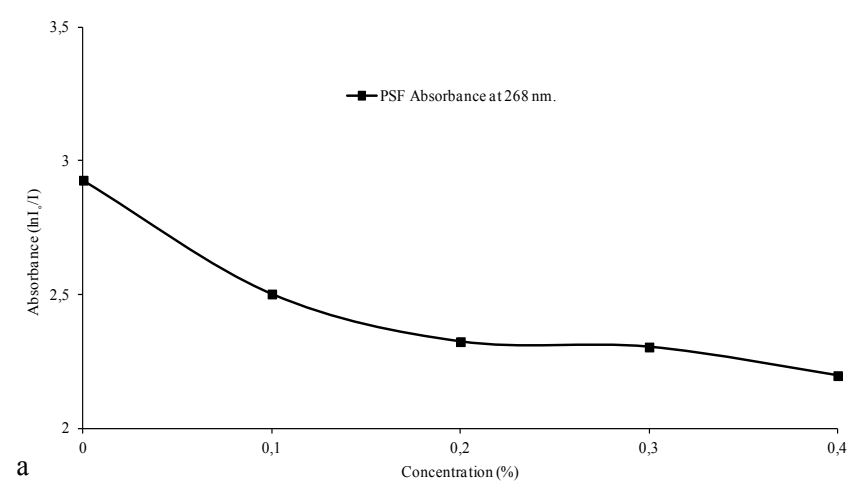

shown in Figure 4a-4c. The storage modulus E' curve for PSF and the $\mathrm{PSF} / 0.2 \% \mathrm{CAB}$ blend showed three main regions, but in the glassy region there is a significant appearance of the three deformation phases (secondary dispersion at $82.6 / 23.9^{\circ} \mathrm{C}, \gamma$-relaxation at $90.4 / 30-40^{\circ} \mathrm{C}$ and $\beta$-relaxation at $187 / 164^{\circ} \mathrm{C}$ ) for pure PSF and the PSF $/ 0.2 \% \mathrm{CAB}$ blend, respectively. It was clear that adding $\mathrm{CAB}$ to PSF led to significant changes in molecular motion, so that two $\gamma$-relaxation processes were observed $\left(30-40^{\circ} \mathrm{C}\right)$ because the substituent in the $\mathrm{CAB}$ component introduced phenylene rings [30]. At $187 / 164^{\circ} \mathrm{C}$, the $\mathrm{E}^{\prime}$ curve for pure PSF and PSF/0.2\% CAB went into the transition region with a steep slope in order to meet with the tan $\delta$ curve at the glass transition temperature $\left(\mathrm{T}_{\mathrm{g}}\right)$ region for each curve, after that went into the rubbery region. The melt temperature of PSF was $220^{\circ} \mathrm{C}$, which has been observed in several experiments. The sulfone with two neighboring benzene rings in PSF contains a highly conjugated diphenyl structure, with significant rigidity of the molecular chains of pure PSF, which led to a high $\mathrm{T}_{\mathrm{g}}$ at $177.3^{\circ} \mathrm{C}$, with the peak of $\tan \delta$ curve within the rubbery region $[31]$.

The increase in the modulus value for the PSF/0.2\% CAB blend indicated improved storage of potential energy but decrease in $\mathrm{T}$ value, so the addition of $\mathrm{CAB}$ increased stiffness and made the blend technologically compatible to some extent even though molecular level

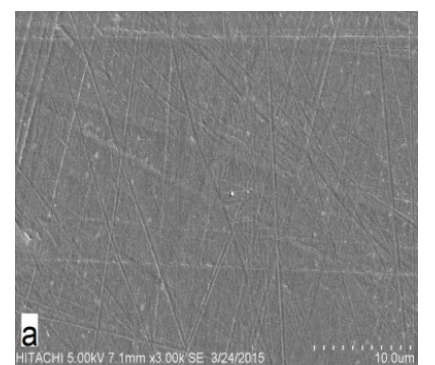

(a)

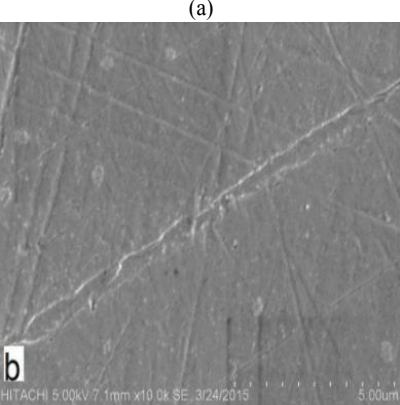

(b)

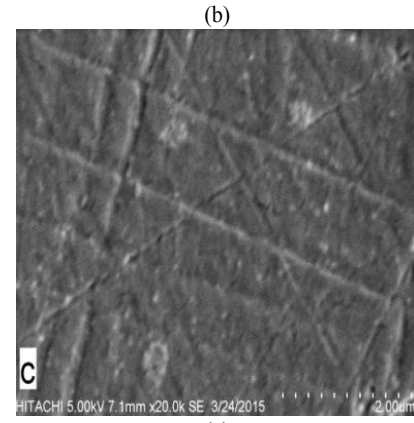

(c)

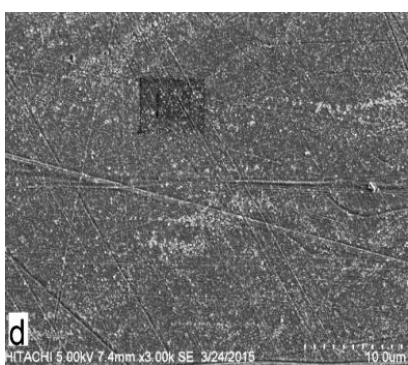

(d)
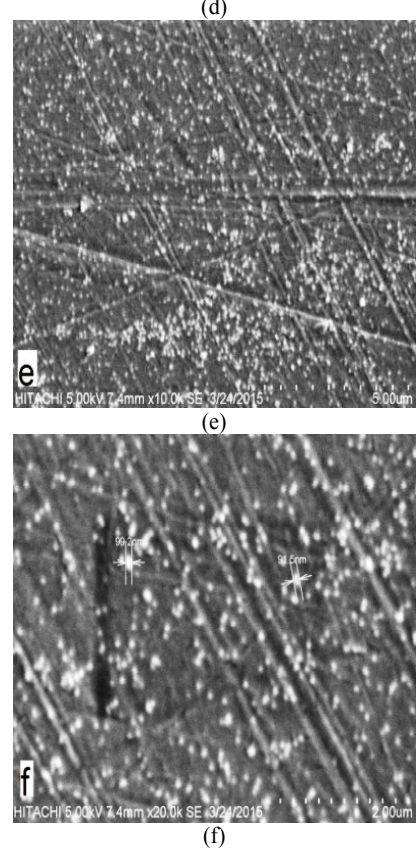

Figure 2: SEM images for PSF and PSF-CAB $0.2 \%$ blend with different scale bar (a) PSF $/ 10 \mu \mathrm{m}$. (b) PSF/5 $\mu \mathrm{m}$. (c) PSF/2 $\mu \mathrm{m}$. (d) PSF-CAB0.2\%/10 $\mu \mathrm{m}$. (e) PSF-CAB0. $\% / 5 \mu \mathrm{m}$. (f) PSF-CAB0. $\% / 2 \mu \mathrm{m}$ (particle measure). 
Citation: Raouf RM, Wahab ZA, Ibrahim NA, Talib ZA (2015) Polysulfone/Cellulose Acetate Butyrate Environmentally Friendly Blend to minimize the Impact of UV Radiation. J Material Sci Eng 5: 219. doi:10.4172/2169-0022.1000219
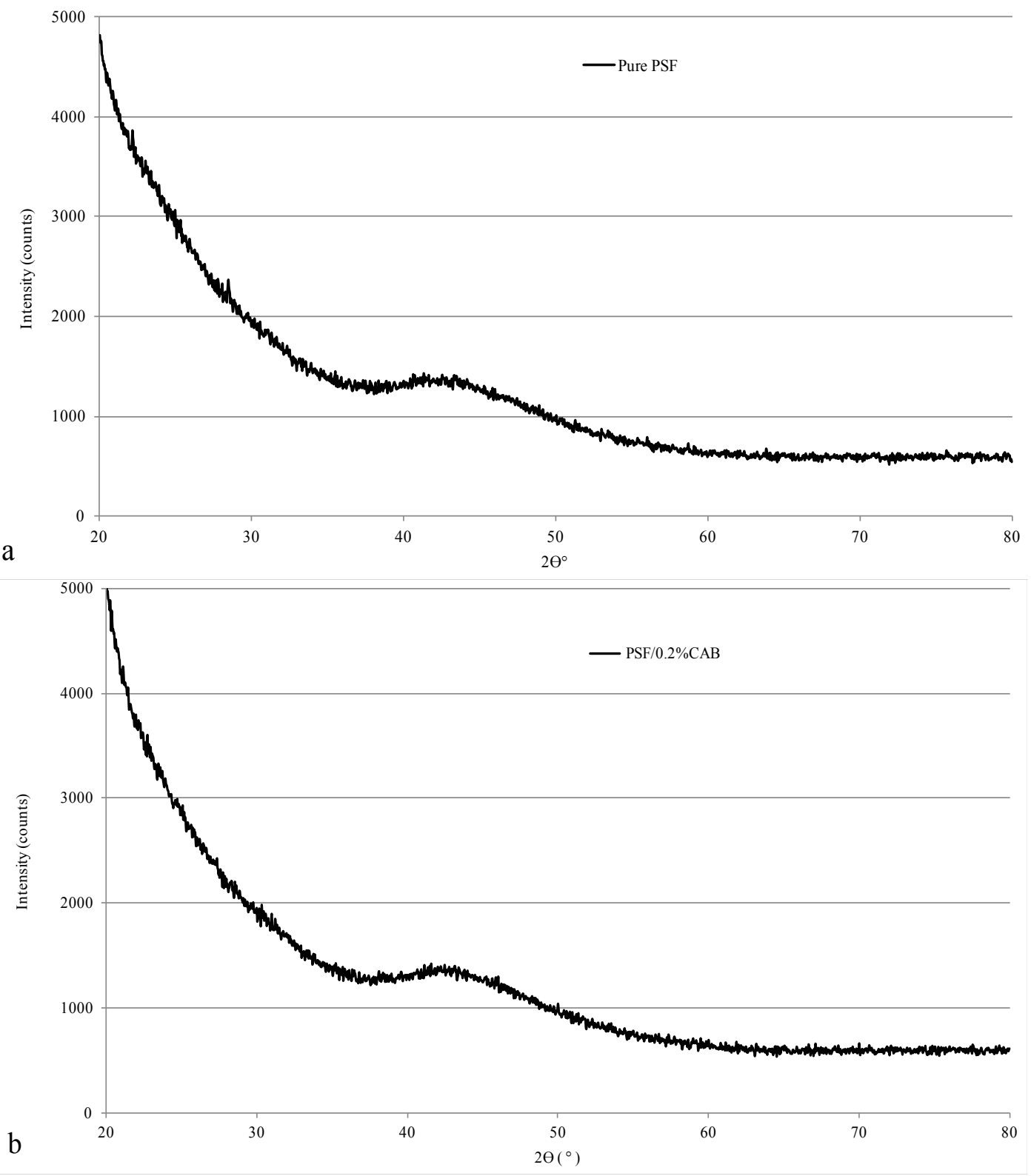

Figure 3: XRD pattern for; (a) pure PSF (b) PSF/0.2\%CAB.

miscibility could not be achieved [28,32].

The position of a peak maximum in the $\tan \delta$ versus temperature curve can be attributed to $\mathrm{Tg}$. It was seen that the addition of $0.2 \% \mathrm{CAB}$ shifted Tg of pure PSF towards a lower value by about $15^{\circ} \mathrm{C}$ Figure $4 \mathrm{c}$. This result suggested that the presence of $\mathrm{CAB}$ molecules caused an increase of molecular mobility in PSF at high temperatures near to $\mathrm{T}_{\mathrm{g}}$ due to decrease in van der Waals bonding forces between PSF and CAB chains [33].

\section{Thermogravimetric analysis}

The thermogravimetric analysis (TGA) and derivative thermogravimetry (DTG) diagrams for pure PSF and the PSF $/ 0.2 \%$ $\mathrm{CAB}$ blend are shown in Figures $5 \mathrm{a}$ and $5 \mathrm{~b}$. All the DTG peaks represent degradation point for each stage. The total weight loss for pure PSF amounted to $\sim 27 \%$ from $89^{\circ} \mathrm{C}-245^{\circ} \mathrm{C}$ and for the PSF $/ 0.2 \% \mathrm{CAB}$ blend was $\sim 5 \%$ from 70 to $430^{\circ} \mathrm{C}$, due to the residual water bound to the hydrophilic imidazole moieties [33]. Pure PSF (Figure 5a), showed a lower degradation temperature at $389^{\circ} \mathrm{C}$, because of the loss in sulfonic acid groups and this represents the most important thermal degradation in polymer chains. The second at $527.8^{\circ} \mathrm{C}$ as a result of carbonization of the degraded residuals (polymeric backbone degradation) $[34,35]$. The high degradation temperature at $527.46^{\circ} \mathrm{C}$ for $\mathrm{PSF} / 0.2 \% \mathrm{CAB}$ blend was attributed to decomposition of the imidazole group without phase inversion components $[33,36]$.

It has been observed that there is thermal stability due to $\mathrm{CAB}$ addition therefore $\mathrm{CAB}$ contributed to the improvement of thermal stability of polymer although not change the degree of decomposition of the main chains temperature. The break in each thermogram 
Citation: Raouf RM, Wahab ZA, Ibrahim NA, Talib ZA (2015) Polysulfone/Cellulose Acetate Butyrate Environmentally Friendly Blend to minimize the Impact of UV Radiation. J Material Sci Eng 5: 219. doi:10.4172/2169-0022.1000219
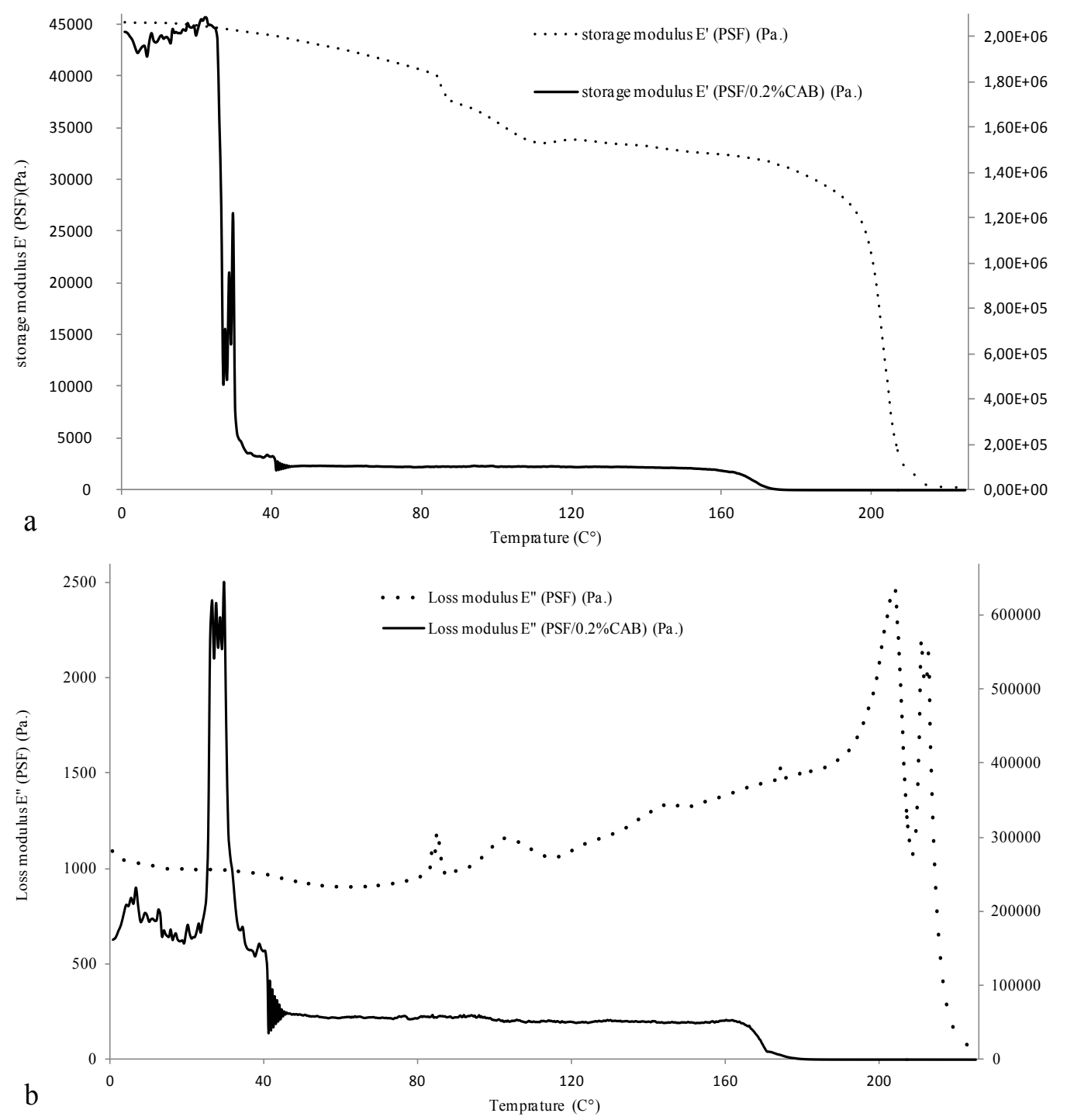

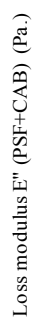

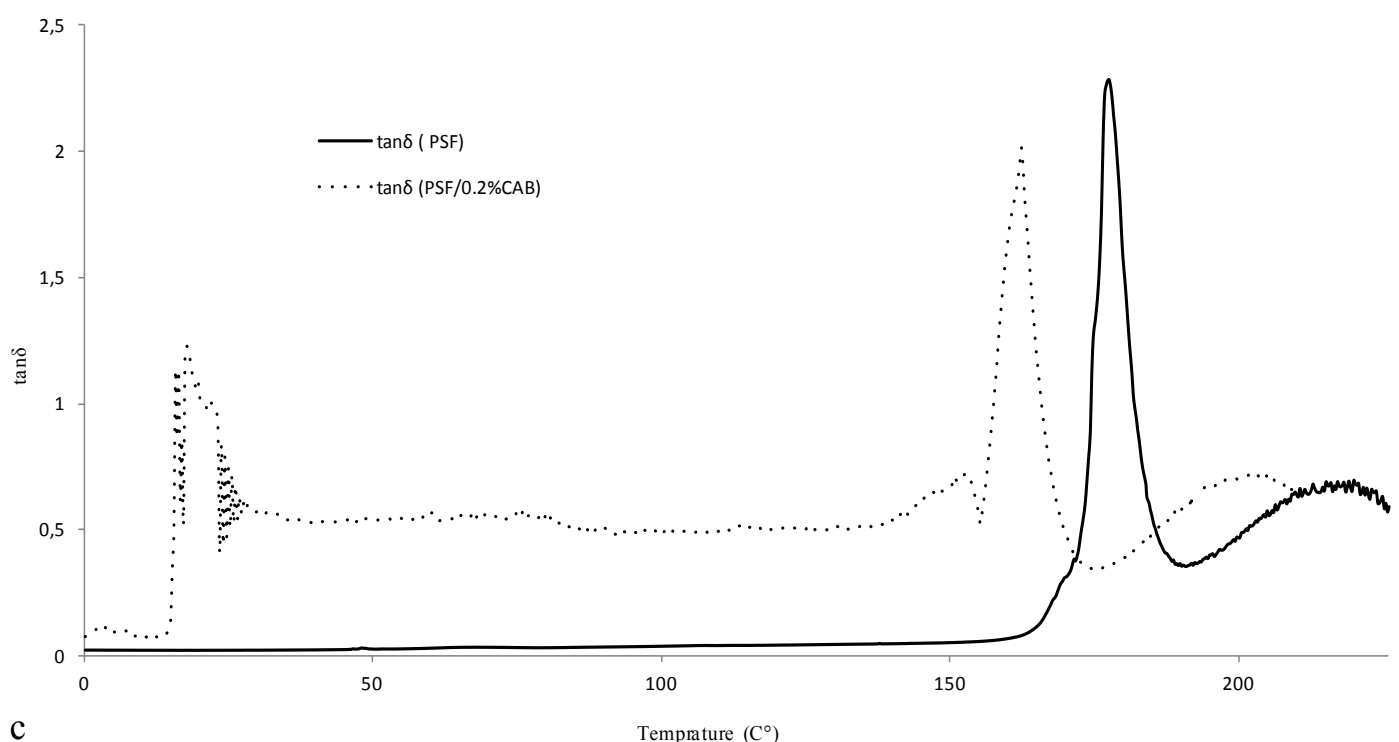

Figure 4: (a) Storage modulus E', (b) loss modulus E" and (c) tan $\delta$ trace for pure PSF and PSF-CAB $0.2 \%$ as a function of temperature by DMA. 


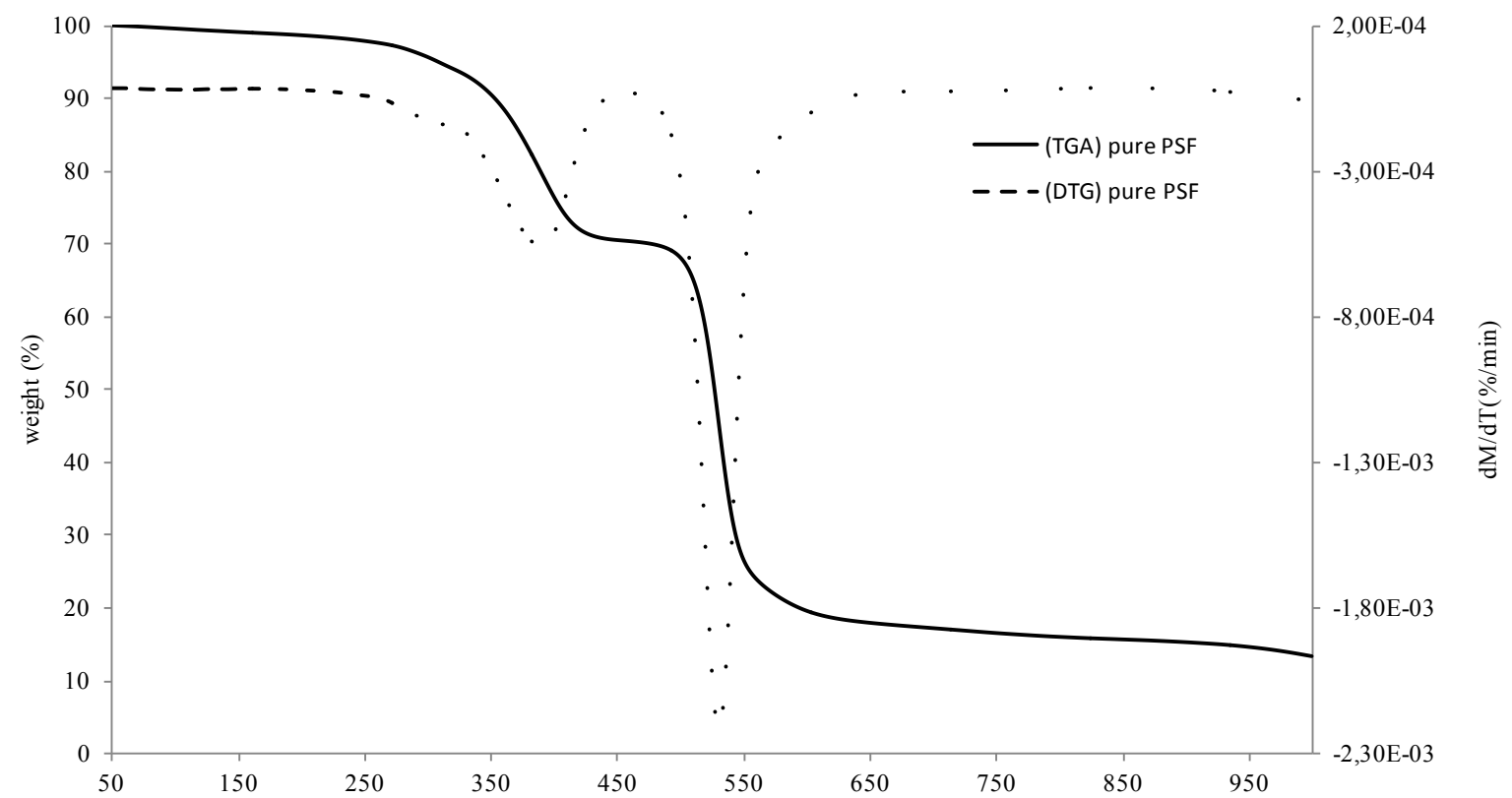

a

Temprature $\left(\mathrm{C}^{\circ}\right)$

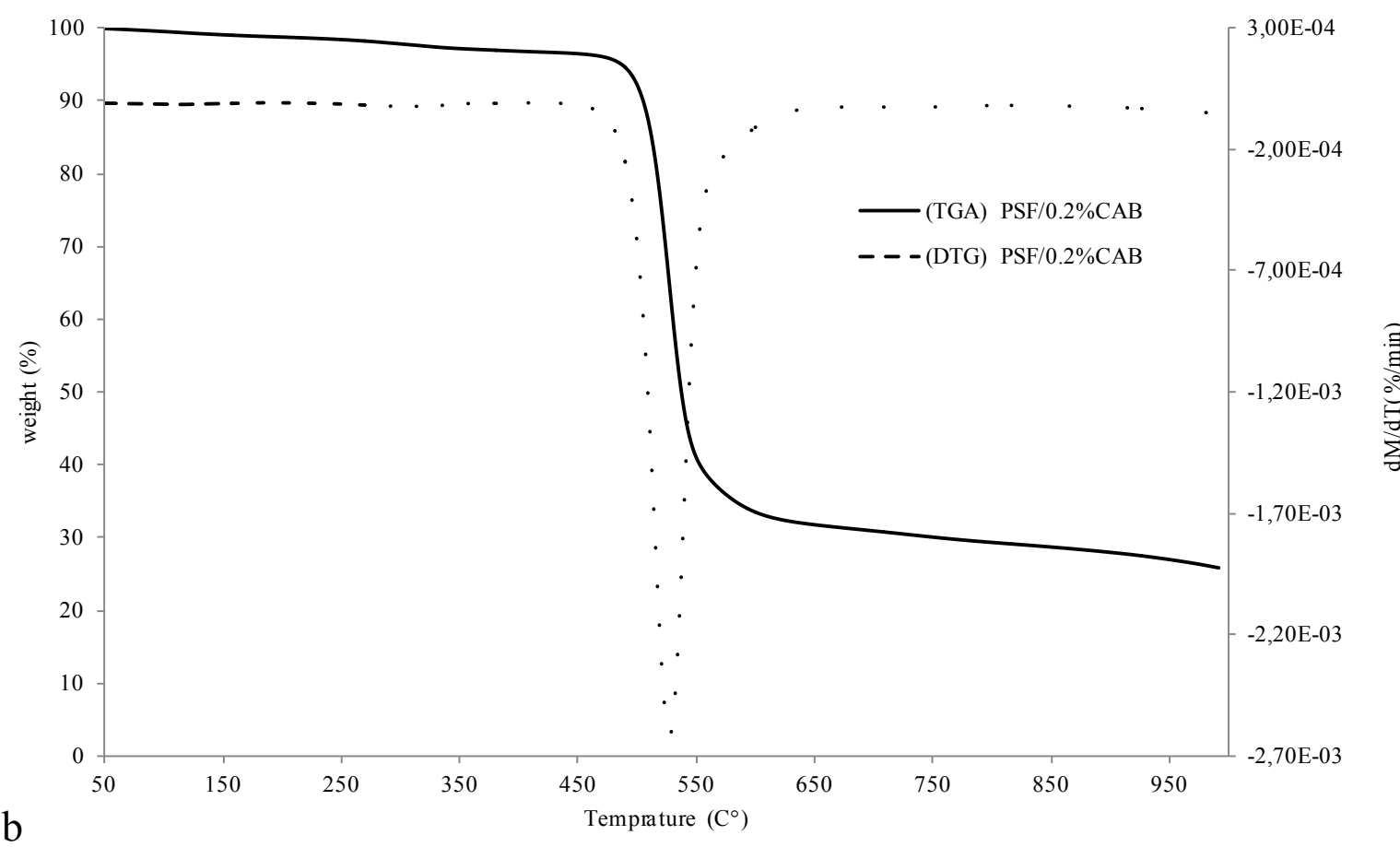

Figure 5: TGA- trace for (a) pure PSF (b) PSF/0.2\% CAB.

indicates the onset of the decomposition process involving a rapid loss in weight [37].

\section{Conclusions}

In this paper, different concentrations of cellulose acetate butyrate $(\mathrm{CAB})$ were mixed with polysulfone (PSF) using Internal Mixer for transparent blend of ultraviolet-visible area, and investigations of some optical, morphological, mechanical and thermal properties were carried out. The study revealed that PSF has absorbance peak at 268 $\mathrm{nm}$ and a transmittance peak at $712.5 \mathrm{~nm}$. The value of these peaks decreases with increasing CAB concentration in PSF. The addition of $\mathrm{CAB}$ to PSF does not change the random structure of the blend, and this seems clear in the sample transparency. It was found that PSF $/ 0.2 \%$ $\mathrm{CAB}$ blend representing low ultraviolet light absorption and high transparency, for this purpose, was chosen as the best concentration. The PSF $/ 0.2 \%$ CAB blend showed an obvious thermal stability with an increase in the value of the modulus, but the value of the glass transition temperature decreased after adding $\mathrm{CAB}$. The properties of 
Citation: Raouf RM, Wahab ZA, Ibrahim NA, Talib ZA (2015) Polysulfone/Cellulose Acetate Butyrate Environmentally Friendly Blend to minimize the Impact of UV Radiation. J Material Sci Eng 5: 219. doi:10.4172/2169-0022.1000219

Page 7 of 7

the blends were a function of CAB concentration in PSF. Additionally; environmentally-friendly $\mathrm{CAB}$ improved the PSF properties while maintaining the transparency of the samples, at least to some extent.

\section{References}

1. Rauwendaal C (2014) Polymer extrusion. Carl Hanser Verlag GmbH Co KG Germany.

2. Rauwendaal CJ (1981) Analysis and experimental evaluation of twin screw extruders. Polymer Engineering \& Science 21: 1092-1100.

3. White JL (1991)Twin Screw Extrusion: Technology and Principles.Hanser Publishers, New York.

4. Armentano I, Fortunati E, Burgos N, Dominici F, Luzi F, et al. (2015) Processing and characterization of plasticized PLA/PHB blends for biodegradable multiphase systems. Express Polymer Letters 9: 583-596.

5. Imre B, Renner K, Pukánszky B (2014) Interactions, structure and properties in poly (lactic acid)/thermoplastic polymer blends. Express Polymer Letters 8 : 2-14.

6. Chen Y, Yuan D, Xu C (2014) Dynamically vulcanized biobased polylactide/ natural rubber blend material with continuous cross-linked rubber phase. ACS applied materials \& interfaces 6: 3811-3816

7. Arrieta MP, Lopez J, Hernández A, Rayón E (2014) Ternary PLA-PHBLimonene blends intended for biodegradable food packaging applications. European Polymer Journal 50: 255-270.

8. Yu L, Dean K, Li L (2006) Polymer blends and composites from renewable resources. Progress in polymer science 31: 576-602.

9. Yu L (2009) Biodegradable polymer blends and composites from renewable resources. John Wiley \& Sons, USA.

10. Meyer LWA, Gearhart WM (1951) Ultraviolet Inhibitors for Cellulose AcetateButyrate Plastics. Phenyl Hydroxybenzoates, Hydroxyphenyl Benzoates and their Methyl Ethers. Industrial \& Engineering Chemistry 43: 1585-1591.

11. Meyer WC (1979) Refinishing automobile and truck bodies, Google Patents.

12. Tachibana $Y$, Truong Gianga NT, Ninomiyaa F, Funabashia M, Kuniokaa M (2010) Cellulose acetate butyrate as multifunctional additive for poly (butylene succinate) by melt blending: Mechanical properties, biomass carbon ratio, and control of biodegradability. Polymer Degradation and Stability 95: 1406-1413.

13. Laskar J, Vidala F, Ficheta O, Gauthier C, Teyssié D (2004) Synthesis and characterization of interpenetrating networks from polycarbonate and cellulose acetate butyrate. Polymer 45: 5047-5055.

14. Noshay A, McGrath JE (2013) Block copolymers: Overview and critical survey Elsevier Science, Burlington.

15. Lane SL, Lindstrom RL, Cameron JD, Thomas RH, Mindrup EA, et al. (1986) Polysulfone corneal lenses. Journal of Cataract \& Refractive Surgery 12: 50-60.

16. Rupiasih NN, Suyanto H, Sumadiyasa M,Wendri N (2013) Study of Effects of Low Doses UV Radiation on Microporous Polysulfone Membranes in Sterilization Process. Open Journal of Organic Polymer Materials 3: 12.

17. Peeling J, Clark DT (1981) Photooxidation of the surfaces of polyphenylene oxide and polysulfone. Journal of Applied Polymer Science 26: 3761-3772.

18. Gesner B, Kelleher $\mathrm{P}(1968)$ Thermal and photo-oxidation of polysulfone. Journal of Applied Polymer Science 12: 1199-1208.

19. Abouelezz M, Waters PF (1978) Studies on the Photodegradation of Poly (methyl methacrylate) DTIC Document.

20. Charlesby A, Thomas DK (1962) Comparison of the Effects of Ultra-Viole and Gamma Radiation in Polymethylmethacrylate. Proceedings of the Royal Society of London. Mathematical and Physical Sciences 269: 104-124.

21. Michelson J, Werner L, Ollerton A, Leishman L, Bodnar Z (2012) Light scattering and light transmittance in intraocular lenses explanted because of optic opacification. Journal of Cataract \& Refractive Surgery 38: 1476-1485.
22. Silverstein RM, Bassler GC, Morrill TC (1991) Spectrometric identification of organic compounds. John Wiley \& Sons, USA

23. Bower DI (2002) An introduction to polymer physics. Cambridge University Press, India.

24. Guo HF, Packirisamy S, Mani RS, Aronson CL, Gvozdic NV, et al. (1998) Compatibilizing effects of block copolymers in low-density polyethylene/ polystyrene blends. Polymer 39: 2495-2505.

25. Robeson L (2014) Historical Perspective of Advances in the Science and Technology of Polymer Blends. Polymers 6: 1251-1265.

26. Elizalde-Pena EA, Flores-Ramirezd N, Luna-Barcenasa G,Vásquez-Garcíab $\mathrm{SR}$, Arámbula-Villaa G, et al. (2007) Synthesis and characterization of chitosan-g-glycidyl methacrylate with methyl methacrylate. European Polymer Journal 43: 3963-3969.

27. Silvestre C, Cimmino S, Martuscelli E (1987) Poly (ethylene oxide)/poly (methy methacrylate) blends: influence of tacticity of poly (methyl methacrylate) on blend structure and miscibility. Polymer 28: 1190-1199.

28. Lufrano F, Squadrito G, Patti A, Passalacqua E (2000) Sulfonated polysulfone as promising membranes for polymer electrolyte fuel cells. Journal of Applied Polymer Science 77: 1250-1256.

29. Menard KP (2008) Dynamic mechanical analysis: A practical introduction. (2 eds.) CRC press, USA

30. Lee KJ, Jho JY, Kang YS, Won J, Dai Y, et al. (2003) Gas transport and dynamic mechanical behavior in modified polysulfones with trimethylsilyl groups: Effect of degree of substitution. Journal of membrane science 223: 1-10.

31. Zhang J, He J (2002) Interfacial compatibilization for PSF/TLCP blends by a modified polysulfone. Polymer 43: 1437-1446.

32. Merenga AS, Katana GA (2010) Katana Dynamic mechanical analysis of PMMA-cellulose blends. International Journal of Polymeric Materials and Polymeric Biomaterials 60: 115-123.

33. Said KA, Amiinu IS, Zhang H, Pan M (2014) Functionalized Polysulfones as an Alternative Material to Improve Proton Conductivity at Low Relative Humidity Fuel Cell Applications. Chemistry and Materials Research 6: 19-29.

34. Krishnaswamy RK, Wadud SEB, Baird DG (1999) Influence of a reactive terpolymer on the properties of in situ composites based on polyamides and thermotropic liquid crystalline polyesters. Polymer 40: 701-716.

35. Momeni S, Pakizeh M (2013) Preparation, characterization and gas permeation study of PSf/MgO nanocomposite membrane. Brazilian Journal of Chemical Engineering 30: 589-597.

36. Subrahmanyan S (2003) An Investigation of Pore Collapse in Asymmetric Polysulfone Membranes. Virginia Polytechnic Institute and State University.

37. Tosh B (2011) Thermal analysis of cellulose esters prepared from different molecular weight fractions of high a-cellulose pulp. Indian Journal of Chemical Technology 18: 451-457. 